International Journal of Advanced Biological and Biomedical Research

Available online at http:www.ijabbr.com

Volume 7, Issue 3 (2019) pp. 255-262

Original Article

\title{
Risk Factors of Gangrenous Cholecystitis in Patients with Acute Cholecystitis: A Cross-Sectional Study
}

\author{
Mohamad Kazem Shahmoradi' ${ }^{1}$, Mehrdad Mirzaei Roozbahani ${ }^{1, *}$, Jafar \\ Mehri $^{2}$, Arefe Qolampoor ${ }^{2}$, Bahram Nasiri3 ${ }^{3}$ Fatemeh Pakmehr ${ }^{3}$ \\ ${ }^{1}$ Assistant Professor, Department of General Surgery, Lorestan University of medical \\ Sciences, Khorramabad, Iran \\ ${ }^{2}$ Resident of General Surgery, Department of General Surgery, Lorestan University of \\ medical Sciences, Khorramabad, Iran \\ ${ }^{3}$ Medical Student, Student Research Committee, Lorestan University of medical Sciences, \\ Khorramabad, Iran \\ *Corresponding Author E-mail: Mehrdad.m.roozbahani@gmail.com
}

Received: 26 March 2019, Revised: 16 May 2019, Accepted: 22 May 2019

\begin{abstract}
Introduction: The aim of this study was to determine factors affecting the development of acute cholecystitis toward gangrenous cholecystitis in an Iranian society; so that, the early diagnosis could pave the way for better management of this disorder.

Materials and methods: In this cross-sectional study, all patients who underwent cholecystectomy in the educational hospitals of Khorramabad from August 2013 to August 2016 were included in the study regardless of their age range. The diagnosis of acute cholecystitis in these patients was based on the presence of Murphy's sign, mass or pain or tenderness of RUQ, presence of leukocytosis, fever, and ultrasound findings of Cholelithiasis, increased gallbladder thickness, or fluid accumulation around the gallbladder. The data collected in each patient included demographic data, underlying illnesses, positive history and physical examination prior to surgery, early laboratory findings and preoperative imaging findings. Finally, patients were divided into two groups of acute Cholecystitis and Gangrenous Cholecystitis based on pathological findings after cholecystectomy. The data were finally analyzed using SPSS software.
\end{abstract}

Results: 51 patients were examined during the study. Histological studies indicated the presence of microscopic evidence of acute cholecystitis in all patients, of which 19 (37.25\%) had histological evidence of Gangrenous Cholecystitis. In this study, nine variables that could be effective on the prognosis of acute cholecystitis and its progression toward the Gangrenous Cholecystitis were identified. These variables included age, white blood cell count, diabetes mellitus and coronary artery disease, fluid accumulation around gallbladder, aspartate aminotransferase, alanine aminotransferase, alkaline phosphatase, and lipase. Finally, multivariate analysis was performed using logistic regression. It was found that the age of betes mellitus. Also, was effective in the development of dia $\geq 51$ $\mathrm{WBC} \geq 15 \mathrm{k} / \mathrm{cmm}$ were independently effective on the prognosis of acute cholecystitis. Conclusion: In this study, it was observed that high age, diabetes mellitus and leukocytosis 
could lead to the development of acute cholecystitis toward Gangrenous Cholecystitis, a finding that requires more extensive studies with more sample size.

Key words: Acute cholecystitis, Gangrenous Cholecystitis, Risk factors.

\section{Introduction}

Gallstone is the most common biliary system disorder that leads to hospitalization (Festi et al., 1999). The disease nowadays imposes a significant economic burden on the health system even in western countries, where it is said that 10 to 20 percent of people in European and American societies suffer from gallstones (Lammert et al., 2005; Völzke et al., 2005). Two percent of patients with gallstones have been diagnosed annually and 15\% of them suffer from acute cholecystitis (Halldestam et al., 2004; Gracie et al., 1982). Acute cholecystitis can be considered as the most common complication of biliary stones (Sangeeta et al., 2000) which, severe type called Gangrenous Cholecystitis or necrotizing, requiring emergency cholecystectomy. In other words, Gangrenous Cholecystitis is a type of acute cholecystitis with transmural inflammation, mucosal absence and necrosis of the gallbladder wall. The incidence of this complication in patients with acute cholecystitis is between 2\% and 30\% (Morfin et al., 1968; Stefanidis et al., 2005), with high mortality and high morbidity (0.2-0.9\%) (Kimura et al., 2007). Various studies on Gangrenous Cholecystitis of male gender have indicated high age, leukocytosis, cardiovascular disease, and diabetes as a risk factor for the development of Gangrenous Cholecystitis (Hunt et al., 2000; Fagan et al., 2003; Aydin et al., 2006; Merriam et al., 1999), which early diagnosis and treatment of this disorder causing significant reduction in mortality and morbidity (Fry et al., 1981). However, what makes Gangrenous Cholecystitis a serious problem is the difficulty of detecting it before surgery. For example, in the study of (Teefy et al., 1991) 48\% of patients with histologic findings after cholecystectomy were confirmed by Gangrene cholecystitis, lacking clinical or clinical evidence for the benefit of this complication (Teefy et al., 1991). That is why in 2010, Yacob and colleagues introduced a grading system based on age, gender, heart rate, white blood cell count, and gallbladder thickness in ultrasound to detect gangrenous cholecystitis (Yacoub et al., 2010). Guidelines Tokyo (Tg13) has also introduced a complex grading system based on clinical, laboratory, and radiological criteria to determine the severity of acute cholecystitis (Mok et al., 2014). However, the complexity of these grading systems, which makes it impossible to use them in many cases on the one hand, and the limited studies conducted in our country about the prognostic factors of Gangrene cholecystitis before surgery on the other hand lead us to identify these factors in an Iranian society and determine patients needing emergency intervention with designing a study.

\section{Materials and methods}

\section{Studied Patients}

In this cross-sectional study, all patients (51 patients) who underwent cholecystectomy in the educational hospitals of Khorramabad from August 2013 to August 2016 are included in the study regardless of their age range. At the beginning of this study, a complete description has been given to all patients and, if necessary, their companions. 


\section{Procedure}

After obtaining a letter of consent for taking part in the study, a history and initial examinations has been taken and the necessary steps to diagnose acute cholecystitis has also been requested. The diagnosis of acute cholecystitis in these patients have been based on the presence of Murphy's sign, mass or pain or tenderness of RUQ, presence of leukocytosis, fever, and ultrasound findings of Cholelithiasis, increased gallbladder thickness, or fluid accumulation around the gallbladder. Initial treatments have been based on approved protocols in general surgery departments, including prescriptions of intravenous fluids, intravenous antibiotics, and analgesics. Acute cholecystectomy indications are also identified based on reference books and with the opinion of general surgery experts. Data collected in each patient include demographic information (age, sex, race), underlying illnesses (diabetes mellitus, coronary artery disease, hyperlipidemia), positive history and preoperative physical examination (pain or mass or tenderness RUQ, nausea, vomiting, fever), early laboratory findings (white blood cell count, BUN, creatinine, AST, ALT, albumin, alkaline phosphatase, bilirubin, amylase, lipase), and preoperative imaging (ultrasound) findings. Finally, patients have been divided into two groups of acute cholecystitis and Gangrenous Cholecystitis based on pathological findings after cholecystectomy.

\section{Data analysis}

Data are finally entered into SPSS software version 11.5 and descriptive statistics and chisquare test have been used to analyze the data. Estimation of the odds ratio has been used to estimate the severity of the relationships by calculating the $95 \%$ confidence interval. In cases of PV $\leq 0.1$, multivariate analysis has also been performed using logistic regression to determine whether the variables studied independently predicted the presence of acute cholecystitis or not?

\section{Ethics approval and consent to participate}

Informed consent has been obtained from all individuals included in this study. The research related to human use has been complied with all the relevant national regulations, institutional policies and in accordance the tenets of the Helsinki Declaration, and has been approved by the ethics committee of Lorestan University of Medical Sciences.

\section{Results}

During the study, 51 patients undergoing cholecystectomy have been diagnosed with acute cholecystitis. Histological studies on removed gallbladder samples reveal the presence of microscopic evidence of acute cholecystitis in all patients, of which 19 (37.25\%) have histological evidence of Gangrenous Cholecystitis. Demographic information for patients is presented in Table 1.

One-variable analysis in this study has been performed using chi-square test which finally, nine variables with a significant level of less than 0.1 detected and performed based on multivariate analysis for these variables that could affect the prognosis of cholecystitis. These variables include age $(\mathrm{OR}=4.3, \mathrm{p}=0.03)$, white blood cell count (WBC) $(\mathrm{OR}=4.8$, $\mathrm{p}=0.003)$, diabetes mellitus $(\mathrm{OR}=2.78, \mathrm{p}=0.003)$, Coronary arteries disease $(\mathrm{OR}=3.14$, $\mathrm{p}=031)$, fluid accumulation around the gallbladder (OR=9.1, $\mathrm{p}=0.045)$, aspartate 
aminotransferase $(\mathrm{OR}=0.38, \mathrm{p}=0.02)$, alanine aminotransferase $(\mathrm{OR}=0.31, \mathrm{p}=0.004)$, Alkaline phosphatase $(\mathrm{OR}=0.27, \mathrm{p}=0.014)$ and lipase $(\mathrm{OR}=0.46, \mathrm{p}=0.04)$. In the multivariate analysis, aspartate aminotransferase has been discarded; because, aspartate aminotransferase and alanine aminotransferase have a strong correlation with each other (Spearmen correlation coefficient $=0.824$, and $\mathrm{P}$ value of alanine aminotransferase is lower than $P$ value of aspartate aminotransferase).

Table 1. Demographic information of patients

\begin{tabular}{|c|c|c|c|}
\hline \multicolumn{2}{|c|}{ Variable } & \multirow{2}{*}{$\begin{array}{c}\begin{array}{c}\text { Acute cholecystitis } \\
\text { N (\%) }\end{array} \\
0(0)\end{array}$} & \multirow{2}{*}{$\begin{array}{c}\text { Gangrenous Cholecystitis } \\
\text { N (\%) } \\
0(0)\end{array}$} \\
\hline \multirow{5}{*}{ Age } & $\geq 20$ & & \\
\hline & $20-30$ & $6(11.76)$ & $0(0)$ \\
\hline & $30-40$ & $4(7.84)$ & $0(0)$ \\
\hline & $40-50$ & $8(15.69)$ & $3(15.79)$ \\
\hline & $50 \geq$ & $33(64.71)$ & $16(84.21)$ \\
\hline \multirow{2}{*}{ Gender } & Male & $39(76.47)$ & $16(84.21)$ \\
\hline & Female & $12(23.53)$ & $3(15.79)$ \\
\hline \multirow{3}{*}{ Race } & Lor people & $24(47.06)$ & $9(47.37)$ \\
\hline & Lak people & $23(45.10)$ & $9(47.37)$ \\
\hline & Others & $4(7.84)$ & $1(5.26)$ \\
\hline
\end{tabular}

Finally, multivariate analysis has been carried out using logistic regression, the results of which are shown in Table 2. According to this in the age of 51 or older, diabetes mellitus and $\mathrm{WBC} \geq 15 \mathrm{k} / \mathrm{cmm}$ are affective in the prognosis of cholecystitis, independently.

Table 2. Multivariate Analysis of Factors Affecting the Prognosis of Cholecystitis

\begin{tabular}{lll}
\hline Variable & Odds ratio (95\% CI) & P Value \\
\hline Age $\geq 51$ & $1.12(0.98-1.53)$ & 0.031 \\
WBC $\geq 15 \mathrm{~K} / \mathrm{cmm}$ & $5.1(4.1-6.4)$ & 0.002 \\
Diabetes Mellitus & $2.8(1.8-4.21)$ & 0.038 \\
Coronary arteries & $2.27(0.83-6.23)$ & 0.283 \\
Fluid accumulation around the gallbladder & $12.7(1.01-298.02)$ & 0.211 \\
ALT $\geq 50 \mathrm{U} / \mathrm{L}$ & $0.28(0.11-0.85)$ & 0.048 \\
Alk $\geq 200 \mathrm{U} / \mathrm{L}$ & $0.21(0.12-1.02)$ & 0.014 \\
\hline
\end{tabular}

\section{Discussion}

In this study, patients over the age of 51 have been at greater risk for Gangrenous Cholecystitis. This finding is in line with the results of studies conducted by other researchers (Bedirli et al., 2001; Fagan et al., 2003; Ganapathi et al., 2015). On the other hand, in a study by (Girgin et al., 2006), it is also noted that age over 51 is associated with higher mortality and morbidity in patients with cholecystitis (Girgin et al., 2006). However, the thing that attaches great significance to the high age of patients with acute cholecystitis is the difficulty in diagnosing acute biliary ducts in these patients due to the limited degree of classic clinical manifestations. In a study by (Morrow et al., 1978), it was pointed out that the incidence of abdominal pain in older patients (more than sixty years old) with acute 
biliary disease is not consistent with the severity of sepsis. In addition, if these patients undergo non-surgical preservative treatment, the failure probability of the treatment measures will be $97.4 \%$. Therefore, in older patients with septicemia, the acute biliary duct should be considered and rejected; because, there is a risk of Gangrenous Cholecystitis and failure of medical treatment in these patients (Morrow et al., 1978).

Also, the findings of this study indicate that; there is a significant relationship between diabetes mellitus and Gangrenous Cholecystitis, which is consistent with the findings of other studies in this area. In a study, conducted by Nguyen et al. (Nguyen et al., 2004), found that Gangrenous Cholecystitis had a statistically significant relationship with factors such as diabetes mellitus and age over 51 and white blood cell count more than 15,000. Also, other studies (Aydin et al., 2006; Nikfarjam et al., 2011) emphasized the onset of diabetes mellitus as a risk factor for Gangrenous Cholecystitis. In addition, another study (Ganapathi et al., 2015) stated that diabetes mellitus was one of the risk factors for Gangrenous Cholecystitis. The researchers introduced factors such as age, male gender and leukocytosis as other risk factors.

Other findings from this study showed a statistically significant relationship between WBC $\geq 15 \mathrm{k} / \mathrm{cmm}$ and Gangrenous Cholecystitis, which is consistent with the findings of other studies in this regard. In this regard, Rosen and colleagues (Rosen et al., 2002) introduced the main predictors of the disease as white blood cell count $(>9,000)$ and the thickness of the gallbladder wall (>mm4). Also, (Gholipour et al., 2009), in their study (Gholipour et al., 2009), which included 793 patients in 2009, introduced factors affecting the disease as leukocytosis (white blood cells more than 9,000). In addition, different researches (Jethwani et al., 2013; Sultan et al., 2013), identified leukocytosis as a risk factor for laparoscopic cholecystectomy conversion to open surgery. This finding was also emphasized in another study (Shiva, 2017), in which the researcher also cited leukocytosis as a risk factor for disease.

\section{Conclusion}

Following the first Hotchkiss report in 1894, Gangrenous Cholecystitis was defined as severe acute cholecystitis. A remarkable point about Gangrenous Cholecystitis was that although it was not known as a common complication of acute cholecystitis, it undoubtedly should be considered as a seriously challenging problem. A complication that required early diagnosis before surgery to take the necessary therapeutic measures because, Gangrenous Cholecystitis surgery was more difficult. Evidence suggested that in many cases, the diagnosis of Gangrenous Cholecystitis during surgery led to the conversion of laparoscopic cholecystectomy to open cholecystectomy. This could be accompanied by several complications and increased the length of hospitalization.

Regarding this issue and also considering the complexity of existing scoring systems for the diagnosis of cholecystitis and the prediction of its severity, and on the other hand, due to the limited studies conducted in our country on the factors affecting the development of acute cholecystitis toward Gangrenous Cholecystitis, it is suggested that other factors affecting this disease be investigated in order to provide a precise basis for the accurate identification of patients requiring emergency intervention and consequently reducing health costs by identifying factors in Iranian society.

\section{Acknowledgements}


We hereby appreciate the sincere help of the hardworking staff of the OR and laboratory wards of Shohada Ashayer hospital in Khorramabad for helping us in conducting the present study.

\section{Conflict of interests}

The authors declare no conflict of interests.

\section{References}

Aydin, C, Altaca, G, Berber, I, Tekin, K, Kara, M, Titiz, I. (2006). Prognostic parameters for the prediction of acute gangrenous cholecystitis. J. Hepatobiliary Pancreat Surg., 13(2):155-159.

Bedirli, A, Sakrak, O, Sozùer, EM, Kerek, M, Güler, I. (2001). Factors effecting the complications in the natural history of acute cholecystitis. Hepatogastroenterology, 48(41):1275-1278.

Fagan, SP, Awad, SS, Rahwan, K, Hira, K, Aoiki, N, Itani, KMF, Berger, DH. (2003). Prognostic factors for the development of gangrenous cholecystitis. Am. J. Surg., 186:481-485.

Festi, D, Sottili, S, Colecchia, A, Attili, A, Mazzella, G, Roda, E, Romano, F. (1999). Clinical manifestations of gallstone disease: Evidence from the multi-center Italian study on cholelithiasis (MICOL). Hepatology, 30(4):839-846.

Fry, DE, Cox, RA, Harbrecht, PJ. (1981). Gangrene of the gallbladder: a complication of acute cholecystitis. South Med. J., 74(6):666-668.

Ganapathi, AM, Speicher, PJ, Englum, BR, Perez, A, Tyler, DS, Zani, S. (2015). Gangrenous Cholecystitis: A Contemporary Review. J. Surg. Res., doi:10.1016/ j.jss.2015.02.058.

Gholipour, Ch, Abolghasemi Fakhree, MB, Alizadeh Shalchi, R, Abbasi, M. (2009). Prediction of conversion of laparoscopic cholecystectomy to open surgery with artificial neural networks. BMC Surgery, 9:13.

Girgin, S, Gedic, E, Taçyıldız, IH, Akgün, Y, Baç, B, Uysal, E. (2006). Factors Affecting Morbidity and Mortality in Gangrenous Cholecystitis. Acta chir. Belg., 106:545-549.

Gracie, WA, Ransohoff, DF. (1982). The natural history of silent gallstones: the innocent gallstone is not a myth. N. Engl. J. Med., 307:798.

Halldestam, I, Enell, EL, Kullman, E, Borch, K. (2004). Development of symptoms and complications in individuals with asymptomatic gallstones. Br. J. Surg., 91:734.

Hunt, DRH, Chu, CK. (2000). Gangrenous cholecystitis in the laparascopic era. Aust. N. Z. J. Surg, 70:428-430.

Jethwani, U, Singh, GJ, Mohil, R, Kandwal, V, Razdan, S, Chouhan, J, Saroha, R, Bansal, N. (2013). Prediction of difficulty and conversion in laparoscopic cholecystectomy. $O A$ Minimally Invasive Surgery, 1(1):2. 
Kimura, Y, Takada, T, Kawarada, Y, Nimura, Y, Hirata, K, Sekimoto, M, Yoshida, M, Mayumi, T, Wada, K, Miura, F, Yasuda, H, Yamashita, Y, Nagino, M, Hirota, M, Tanaka, A, Tsuyuguchi, T, Strasberg, SM, Gadacz, TR. (2007). Definitions, pathophysiology, and epidemiology of acute cholangitis and cholecystitis: Tokyo guidelines. J. Hepatobiliary Pancreat Surg., $14(1): 15-26$.

Lammert, F, Sauerbruch, T. (2005). Mechanisms of disease: the genetic epidemiology of gallbladder stones. Nat. Clin. Pract. Gastroenterol Hepatol, 2(9):423-433.

Merriam, LT, Kanan, SA, Dawes, LG, Angelos, P, Prystowsky, PJB, Renge, RV, Joehl, RJ. (1999). Gangrenous cholecystitis: analysis of risk factors and experience with laparascopic cholecystectomy. Surgery, 126:680-686.

Mok, KWJ, Reddy, R, Wood, F, Turner, P, Ward, JB, Pursnani, KG, Date, RD. (2014). Is C reactive protein a useful adjunct in selecting patients for emergency cholecystectomy by predicting severe/gangrenous cholecystitis. Int. J. Surg., 12:649-653.

Morfin, E, Ponka, JL, Brush, BE. (1968). Gangrenous cholecystitis. Arch. Surg., 96(4):567473.

Morrow, DJ, Thompson, J, Wilson, SE. (1978). Acute cholecystitis in the elderly. Arch. Surg., 113:1149-1152.

Nguyen, L, Fagan, SP, Lee, TC, Aoki, N, Itani, KM, Berger, DH, Awad, SS. (2004). Use of a predictive equation for diagnosis of acute gangrenous cholecystitis. Am. J. Surg., 188:463466.

Nikfarjam, M, Niumsawatt, V, Sethu, A, Fink, MA, Muralidharan, V, Starkey, G, Jones, RM, Christophi, Ch. (2011). Outcomes of contemporary management of gangrenous and nongangrenous acute cholecystitis. HPB (Oxford), 13:551-558.

Rosen, M, Brody, F, Ponsky, J. (2002). Predictive factors for conversion of laparoscopic cholecystectomy. Am. J. Surg., 184(3):2548.

Sangeeta, A, Sreenivasa, J. (2000). Gallstones from gallbladder to gut. Postgrad. Med., 108(3):143-153.

Shiva, A. (2017). Predictive Factors of the Success of Laparoscopic Cholecystectomy in Patients with Acute Cholecystitis Referring to Qazvin Hospital. General Surgery Thesis, Qazvin University of Medical Sciences and Health Services. 2017. [In Persian]

Stefanidis, D, Bingener, J, Richards, M, Schwesinger, W, Dorman, J, Sirinek, K. (2005). Gangrenous cholecystitis in the decade before and after the introduction of laparoscopic cholecystectomy. JSLS, 9(2):169-173.

Sultan, AM, El-Nakeebet, A, Elshehawy, T, Elhemmaly, M, Elhanafy, E, Atef, E. (2013). Risk Factors for conversion during laparoscopic cholecystectomy: retrospective analysis of ten years' experience at a single tertiary referral center. Dig. Surg., 30:51-55. 
Teefy, SA, Baron, RL, Radke, HM, Bigler, SA. (1991). Gangrenous cholecystitis: new observations on sonograph. J. Ultrasound Med., 10:603-606.

Völzke, H, Baumeister, SE, Alte, D, Hoffmann, W, Schwahn, C, Simon, P, John, U, Lerch, MM. (2005). Independent risk factors for gallstone formation in a region with high cholelithiasis prevalence. Digestion, 71(2):97-105.

Yacoub, WN, Petrosyan, M, Sehgal, I, Ma, Y, Chandrasoma, P, Mason RJ. (2010). Prediction of patients with acute cholecystitis requiring emergent cholecystectomy: a simple score. Gastroenterol Res. Pract., 2010:901739.

How to cite this article: Mohamad Kazem Shahmoradi, Mehrdad Mirzaei Roozbahani, Jafar Mehri, Arefe Qolampoor, Bahram Nasiri, Fatemeh Pakmehr. Risk Factors of Gangrenous Cholecystitis in Patients with Acute Cholecystitis: A Cross-Sectional Study. International Journal of Advanced Biological and Biomedical Research, 2019, 7(3), 255-262. Link: http://www.ijabbr.com/article 35292.html 